\title{
Model of the coil steels loading planning problem in railway carriage
}

\author{
D I Maftuhah ${ }^{1 *}$, I Vanany ${ }^{1 * *}$, A R Muchsinin ${ }^{1}$, and D Rahadian ${ }^{2}$ \\ ${ }^{1}$ Department of Industrial Engineering, Institut Teknologi Sepuluh Nopember - Kampus ITS \\ Sukolilo - Surabaya 60111, Indonesia \\ ${ }^{2}$ Krakatau Bandar Samudera, Cilegon, Indonesia \\ *diesta@ie.its.ac.id
}

\begin{abstract}
In this paper, the coil steels loading planning problem in trains is considered. This problem consists of determining the optimal assignment of coil steels to wagon slots of train in order to maximize the total weight of coil steels in railway carriage. Both knapsack problems and linear programming method are used to develop model of coil steels loading planning problem. The comparisons between the subjective adjustment method and the best solution of proposed model were conducted and were found through extensive experimental test of proposed model. The results of proposed model presented that the amount of coils steels that were more than and the weights of coil steels heavier than subjective adjustment method.
\end{abstract}

\section{Introduction}

Efforts to optimize goods to be transported become desirable outcomes by freight practitioners, either by using land transportation modes such as trains and trucks, mass rapid transit (MRT) (1), and bus feeder (2), sea transportation such as containers on ships, as well as ground transportation such as cargo. In optimization research, loading optimization is one of the interesting issues to be studied in the field of logistics and transportation insight. Modes used to transport goods as a transport medium with different carrying capacity and requirements met can cause the optimization model used become unique and different from each other. The transportation process should be signed with responsiveness and efficiency and depends on the different types of handling tools, control systems, and the coordination levels of operator in the terminal/station. Container terminals are a very complex system which requires the development of quantitative methods to support relevant decisions. Planning and control in making decisions are discussed in the field of operational research to obtain an efficient container terminal. There are several related divisions of the optimization approach adapted to different processes within container terminals at ports, including delivery planning, storage, arrangement, and optimization of transportation (3). Most of research were conducted in modelling the loading problem optimization of goods for containers on ships. Some researchers developed the model of containers loading at ports (4). Furthermore, model of container loading in the ship bays in which the containers were placed extending from front to rear position had been constructed (5). The complexity of the model made was on varied constraints such as the weight limit, the location of the delivery destination, the size of the container, the type of the container and the plan of container's placement on ship (6). Related to this research, plan of the container's placement (coil steels) in railway carriage also involved operational decisions which 
were influenced by strategic and tactical decisions about how to plan good transportation of coil steels (in the form of handling equipment for storage areas) and how storage areas were managed (storage strategies used). In addition, in the coil steels loading planning, the station operator also aims to optimize the operation of existing trucks in storage or warehouses by transporting coils steels based on the suitable size according to the truck size and the size of each railway carriage.

However, during this time which is known to researchers, only few research were found in modelling the loading problem optimization of goods in railway carriages, i.e. coil steels in both large size and weight. This research focused and discussed loading problems in case study company which contains coil steel in railway carriage. So far, in the practice of loading coil steel, the company realized that it had not done the loading of coil steel in the optimal amount. The company only used subjectivity when selecting or pinching the coil steel to be loaded for each carriage. Furthermore, case study company is one of companies engaged in freight forwarding or logistics transportation, in which often had experiences in determining the combination of coil steels to be loaded in the optimal solution. While loading the coil steels, there are some decisions that have to be achieved in decision making simultaneously. The types of decisions are to determine the quantity (maximum weight), type of coil steels based on the order received, and lay out position (arrangement) of coil steels in optimal amount. The problem was quite complex so that the manual solving was difficult to get the optimal solution. Thus, a solution to determine coil steels loading planning in optimal amount in railway carriage is required.

Meanwhile, Knapsack problem logic is an optimization logic often used for loading problems. The Knapsack problem is defined as an optimization problem in the selection of goods that can be placed into a container, in which the container has limited space or capacity (7). Benefits provided are for goods which will be loaded into the container in bigger amount and heavier weight so that delivery cost per weight will be cheaper. Mostly, the items to be loaded have different weight and size (length, width, and height). Furthermore, the application of Knapsack problem will help practitioners in managing their goods more efficient and effective (8). Therefore, to fill the existing research gap, it was necessary to conduct research on solving problem by modelling the loading problem optimization of coil steels in railway carriages with Knapsack logic. The practical contribution of this research would help practitioners managing the coil steels loading arrangements in order to many coil steels were delivered in bigger amount and heavier weight. It absolutely would cause the delivery cost of steel tonnage cheaper.

\section{Coil steels loading problem}

In making decisions regarding the plan for loading of coil steels in railway carriage, there were several variables to consider in the loading of coil steels, including delivery destination, weight, type, maximum weight of coil steels. In addition, the location of coil steels in storage might also affect the loading plan (6). This research was conducted to obtain efficiency in every process of loading problems. There were several ways to solve goods loading problems related to optimize the number of railway carriages, minimize handling time, as well as optimize the total weight loaded in each railway carriage (9). The method used was to select the configuration of the train to maximize the utility of the railway carriage and to minimize the total cost (delivery costs for goods loading and setup fees to change the train configuration). In the existing condition, the activities of coil steels loading in railway carriages were controlled by the head of operational logistics services based on case study company. Case study company is one of companies engaged in freight forwarding or logistics transportation and often had problems in determining the combination of coil steels to be loaded in optimal amount. After receiving the coil steels order from the customer, PT Krakatau Steel sent the delivery of the coil steels to case study company. Then, case study company directly communicated with the PT KAI which provided the railway carriages. The coil steels transportation route were departed from PT Krakatau Steel-Cilegon station to Kalimas Surabaya station, where the trip took about 3 days. Meanwhile, there were two requirements fulfilled by PT KAI in the loading process of coil steels, as follows: (1) Capacity of coil steels on each carriage had a maximum load weight ( $\leq 42$ tons), (2) Difference of coil steel weights 
between the front and rear positions of carriage had a maximum weight ( $\leq 2$ tons). The illustration of coil steels loading is presented in the following figure 1.

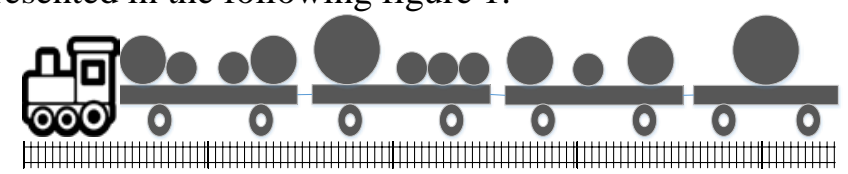

Figure 1. Illustration of Coil Steels Loading.

In real case, the loading process of coil steels only applied operator's subjective adjustment method when selecting or pinching the coil steels to be loaded in each railway carriage. The subjective adjustment method yielded 479.64 tons of the total weight of coil steels for 12 carriages. By applying that method, the company realized that the carriages had not been loaded the coil steels in the optimal amount. There were three constraints considering in decision making simultaneously, such as decision to determine delivery time which met the deadline (the quantity and type of goods based on the order received). The second constraint is decision to determine the quantity of the goods transported regarding maximum weight of the goods. The third constraint is decision to determine optimal layout arrangement of goods into the vehicle. The mathematical model created at the modelling stage is the result of a literature study of cases of loading problems and knapsack problems derived from various references. This modelling aims for adopting existing mathematical models to actual problems in case study company. The model constructed refers to loading containers at ports entitled issues in the development of approaches to container loading (4) and Knapsack Problems: Algorithms and Computer Implementation (7). The mathematical model applying linear programming method in this research has purpose function to maximize total weight of coil steels in each carriage. Optimization model of coil steels loading problem will be able to be applied in related problem with the same conditions/constraints.

\section{Indices}

$i=1, \ldots n \quad$ type of coil steels ( $n$ : number of coil steels demand)

$j=1, \ldots m \quad$ type of railway carriage (m: number of railway carriages -12 units)

$k=1, \ldots o \quad$ position of coil steels placement in each railway carriage (o: number of coil steels

\section{Parameters} placement position in railway carriage - front, middle, and rear position in order)

$\mathrm{Bi} \quad$ weight of each coil steel

$\mathrm{Kj} \quad$ load capacity of coil steels in each carriage ( $\leq 42$ tons)

$T \quad$ the difference of load weight in each carriage between front and rear position ( $\leq 2$ tons)

\section{Decision Variable}

$X_{i j k} \in\{1,0\} \quad$ Placement of coil steels $i$, carriage $j$, position $k$

\section{Coil Steels Loading Planning Problem}

$$
\text { Max }=\sum_{i=1}^{n} \mathrm{X}_{i j k} * \mathrm{~B}_{i}
$$

subject to:

$$
\begin{aligned}
& \sum_{i=1}^{n} \sum_{j=1}^{m} \sum_{k=1}^{o} \mathrm{X}_{i j k} \leq 3 \quad \forall k \neq 2 \\
& \sum_{i=1}^{n} \sum_{j=1}^{m} \mathrm{X}_{i j 1}=\sum_{i=1}^{n} \sum_{j=1}^{m} \mathrm{X}_{i j 3} \\
& \sum_{i=1}^{n} \sum_{j=1}^{m}\left|\mathrm{X}_{i j 1} * \mathrm{~B}_{i}-\mathrm{X}_{i j 3} * \mathrm{~B}_{i}\right| \leq 2
\end{aligned}
$$

$$
\begin{aligned}
& \sum_{i=1}^{n} \sum_{j=1}^{m} \sum_{k=2}^{o} \mathrm{X}_{i j k} \leq 1 \quad \forall k=2 \\
& \sum_{i=1}^{n} \sum_{j=1}^{m} \sum_{k=1}^{o} \mathrm{X}_{i j k} * \mathrm{~B}_{i} \leq 42 \\
& \sum_{i=1}^{n} \sum_{j=1}^{m} \sum_{k=2}^{o} \mathrm{X}_{i j k}=1
\end{aligned}
$$




$$
\sum_{i=1}^{n} \sum_{j=1}^{m} \sum_{k=1}^{o} \mathrm{X}_{i j k} * \mathrm{~B}_{i} \leq 22 \quad \forall k \neq 2 \quad \text { (8) } \quad \mathrm{X}_{i j k} \in\{1,0\}
$$

The objective function (1) attempts to maximize the coil steels loading in each railway carriage. The constraints (2) represent maximum number of coil steels ( $\leq 3$ units) which can be loaded in each carriage for one position only (front or rear position). Constraints (3) keep the placement rule of coil steels in middle position ( $\leq 1$ unit) in railway carriages. Meanwhile, constraints (4) keep the placement rule of coil steels in both front and rear position (if the front position will be loaded by the coil steel, then the rear one has also to be loaded, vice versa). In addition to that, constraints (5) and (6) aim to meet the two requirements of the problem which are previously stated. Constraints (5) limit the maximum weight of coil steels ( $\leq 42$ tons) loaded in each carriage. Constraints (6) keep the difference between coil steels weight that will be placed at front and rear position in each carriage (maximum difference $\leq 2$ tons). Constraints (7) state that only one coil steel will be taken once and be placed in one position only. Constraints (8) limit the maximum weight of coil steels in front or rear position. The last constraint (9) represents that decision variables are in binary number ( 1 and 0$)$.

\section{Solution method proposed}

The problem of this research was solved by proposing Knapsack Algorithm to obtain the optimal solution of coil steels loading problem in railway carriages. The steps are used to solve the problem using Knapsack Algorithm and sample data from some cases are explained as follows:

Step 1: Entry data input of coil steel weight (Knapsack problems logic requires some data input, including: weight \& delivery due date of coil steels (n), number of railway carriages (m), and capacity of each carriage $(\mathrm{Kj})$, as well as some parameters considered in the model and stated above).

Step 2: For all railway carriages, if there are two loads (a pair of coil steels) for front position and also rear position in a carriage, then determine the following conditional decision whether coil steel weight exceeds the carriage capacity. If the weight exceeds the capacity, update the state of chosen coil steel into loaded coil steel. Otherwise, find only one coil steel which can be loaded in carriage, then update its state.

Step 3: Find minimum load for front position and also rear position which can still be loaded (if any), then update total of difference after loaded with the minimum load.

Step 4: Calculate the Knapsack performance and record the total of difference with the ideal difference. After that, iterate step (2) and step (3) until all railway carriages fully loaded or no coil steel to be loaded. Then, stop the process.

\section{Experimental design}

The experimental design is used to compare the performance of mathematical model and Knapsack Algorithm presented above with the logic and condition of the real system. This stage is exactly supposed to check the conformity between the model and the real system which can be presented in verification and validation step. Verification is applied to check conformity between the model and the desirable logic or structure. In the other hand, to check the conformity between the model and the real condition is presented in validation stage.

\subsection{Verification of Knapsack Algorithm}

As stated before, verification is applied to check the consistency and conformity the algorithm against the desirable condition. In this research, this stage was conducted by applying two verification steps. The first step is by applying debug in the stated algorithm with VBA (Visual Basic for Applications) features added in Microsoft Excel in order to conform that the model has feasible solution. The verification result presented that notation of algorithm in VBA features had been already feasible. It means that the constructed model had been verified by the software. Furthermore, second verification stage is conducted by checking the conformity calculation logic in VBA with the Knapsack algorithm 
calculation stage presented in solution method proposed. The smaller dimensions of variables and parameters than the real problem were applied for tested model in verification. The tested data for verification are represented in the following table 1 (a) and (b).

Table 1. Tested Data for Verification of Knapsack Algorithm.

(a) Coil Steels Data

\begin{tabular}{cc}
\hline Type of Coil Steel $i$ & Weight $(\mathrm{Bi})$ in tons \\
\hline 1 & 10,95 \\
2 & 8,99 \\
3 & 8,84 \\
4 & 9,62 \\
5 & 9,58 \\
\hline
\end{tabular}

(b) Railway Carriage Capacity

\begin{tabular}{|c|c|c|c|c|c|}
\hline Carriage $j$ & Position $k$ & $\begin{array}{c}\text { Capacity }(\mathrm{Kj}) \\
\text { in tons }\end{array}$ & $\begin{array}{l}\text { Difference }(\mathrm{T}) \\
|\mathrm{F}-\mathrm{R}| \text { in tons }\end{array}$ & $\begin{array}{l}\text { Maximum } \\
\text { Weight (W) } \\
\text { in tons }\end{array}$ & $\begin{array}{l}\text { Maximum Amount of } \\
\text { Coil Steel (n) in unit }\end{array}$ \\
\hline \multirow{3}{*}{1} & Front (F) & & & 21 & 3 \\
\hline & Middle (M) & 42 & $\leq 2$ & 42 & 1 \\
\hline & Rear (R) & & & 21 & 3 \\
\hline \multirow{3}{*}{2} & Front (F) & & & 21 & 3 \\
\hline & Middle (M) & 42 & $\leq 2$ & 42 & 1 \\
\hline & Rear (R) & & & 21 & 3 \\
\hline
\end{tabular}

The result of verification using tested data can be seen in the following table 2. The computation result shows that there are only three positions chosen among six positions in two carriages probably placed by five coil steels. Three positions chosen in those two carriages are for Carriage 1 filled by Coil Steel 1 and 4 in front position and Coil Steel 2 and 5 in rear position, as well as for Carriage 2 only filled by Coil Steel 3 in middle position. The result presents that the capacity constraints of maximum weight in each carriage were already fulfilled. In addition to that, the difference of weights between front and rear position and the number of coil steels chosen did not break the determined rule. It can be concluded that the Knapsack Algorithm had completely been verified.

Table 2. Verification Result of Knapsack Algorithm.

\begin{tabular}{|c|c|c|c|c|c|c|c|}
\hline $\begin{array}{c}\text { Carriage } \\
j\end{array}$ & $\begin{array}{c}\text { Position } \\
k\end{array}$ & $\begin{array}{l}\text { Type of Coil } \\
\text { Steel } i\end{array}$ & $\begin{array}{l}\text { Weight } \\
\text { (Bi) in } \\
\text { tons }\end{array}$ & $\begin{array}{l}\text { Total } \\
\text { Load } \\
\text { (tons) }\end{array}$ & $\begin{array}{l}\text { Difference } \\
\text { (T) }|\mathrm{D}-\mathrm{B}|\end{array}$ & $\begin{array}{c}\text { Capacity } \\
(\mathrm{Kj}) \text { in } \\
\text { tons }\end{array}$ & Illustration \\
\hline \multirow{2}{*}{1} & Front & 1 dan 4 & $\begin{array}{l}10,95 \\
9,62\end{array}$ & 20,57 & \multirow{2}{*}{2} & 21 & \\
\hline & Rear & 2 dan 5 & $\begin{array}{l}8,99 \\
9,58\end{array}$ & 18,57 & & 21 & \\
\hline 2 & Middle & 3 & 8,84 & 8,84 & 0 & 42 & \\
\hline
\end{tabular}

\subsection{Validation of Knapsack Algorithm}

Validation of Knapsack Algorithm is conducted by conforming the computational logic in VBA features with the numerical/manual calculation (trial and error experiments) stage. Furthermore, the computational results from VBA are compared to the numerical calculation. The models are concluded 
valid if the computational results are equal to the numerical calculation results and there is no constraint breaking the rule. The tested data for validation are equal to the tested data for verification presented in Table 1 (a) and (b). Coil steels data in Table 1 (a) present the value of experimental input data to ease the calculation and to obtain the accurate results. Based on the data, it is necessary to do numerical calculation in determining coil steels placement in each railway carriage position. The result of validation using numerical calculation (trial and error experiments) against Knapsack Algorithm computation of coil steels placement using VBA can be seen in table 3 (a) and (b).

Table 3. Validation Result of Knapsack Algorithm.

(a) Numerical Calculation (Trial and Error Experiment)

\begin{tabular}{ccccccc}
\hline Experiment & Carriage $j$ & Position $k$ & $\begin{array}{c}\text { Type of } \\
\text { Coil Steel } i\end{array}$ & $\begin{array}{c}\text { Weight (Bi) } \\
\text { in tons }\end{array}$ & $\begin{array}{c}\text { Cumulative } \\
\text { Weight (tons) }\end{array}$ & $\begin{array}{c}\text { Total Load } \\
\text { (tons) }\end{array}$ \\
\hline 1 & 1 & Front & 1 & 10,95 & 10,95 & 20,57 \\
2 & 1 & Front & 4 & 9,62 & 20,57 & \\
3 & 1 & Front & 2 & 8,99 & 29,56 & \\
4 & 1 & Rear & 2 & 8,99 & 8,99 & 18,57 \\
5 & 1 & Rear & 5 & 9,58 & 18,57 & \\
6 & 1 & Rear & 3 & 8,84 & 27,41 & 8,84 \\
\hline 7 & 2 & Middle & 3 & 8,84 & 8,84 & 47,98 \\
\hline \multicolumn{7}{c}{ Total Weight of Coil Steels } \\
\hline
\end{tabular}

(b) Computation using VBA Features

\begin{tabular}{|c|c|c|c|c|c|c|}
\hline Number of & Number & & & & & \\
\hline 1 & 5 & $\begin{array}{c}\text { Carriage } \\
j\end{array}$ & $\begin{array}{c}\text { Position } \\
k\end{array}$ & $\begin{array}{c}\text { Type of } \\
\text { Coil Steel } i\end{array}$ & $\begin{array}{l}\text { Total Load } \\
\text { (tons) }\end{array}$ & $\begin{array}{l}\text { Maximum Difference of } \\
\text { Load (42 tons) }\end{array}$ \\
\hline & & 1 & Front & 1 and 4 & 20,57 & 0,43 \\
\hline Run Max-I & $x-M i n$ & 1 & Rear & 2 and 5 & 18,57 & 2,43 \\
\hline & & 2 & Middle & 3 & 8,84 & 12,16 \\
\hline & & Total & Veight of & il Steels & 47,98 & \\
\hline
\end{tabular}

Based on the table above, the allocation result from numerical calculation (trial and error experiments) and Knapsack Algorithm calculation using VBA can give the same results. The output of numerical calculations yielded the total weight of coil steels of 47.98 tons. Meanwhile, the output of VBA computations also yielded the total weight of coil steels of 47.98 tons. Therefore, Knapsack Algorithm constructed to solve coil steels loading planning problem in railway carriages had been valid.

\section{Conclusions}

Based on the research findings above, the mathematical model and Knapsack algorithm has been yielded to overcome the optimization problem of coil steels loading planning in railway carriages. The verified and valid model can be implemented in real case and give the practical benefit. The manager is relatively easier and faster to decide with the optimal arrangement of the coil steels loading problem using the proposed Knapsack model than subjective method. Feasible solutions are expected to be more optimum and efficient results than the existing result using subjective adjustment method (479.64 tons for 12 carriages). The loading problem of coil steels in railway carriages can be developed into experimental design using exact method and Knapsack Algorithm using heuristics method. From both experiments, the comparison could be conducted to obtain which method would yield the optimum solution considering the computational time. Furthermore, this research can also be improved by using other Knapsack algorithms which are suitable for the optimization problems, especially for coil steel loading planning problem in railway carriages. According to the Knapsack algorithm which had been 
constructed in this research, it is necessary to make improvement for the constructed algorithm to accommodate the extreme condition in solving the next problem. In addition to that, because this research is limited to certain parameters, the future research should better consider coil steels which have earlier due date of delivery.

\section{References}

1. Vanany I, Khoiri M, Hartanto D, Imani PN. Willingness to Pay for Surabaya Mass Rapid Transit (SMART) Options. Procedia Manuf. 2015 Jan 1;4:373-82.

2. Vanany I, Rosyadi RS, Ciptomulyono US, Hartanto D, Khoiri M. Feeder bus routing problem using a genetic algorithm: Surotram case study. In: 2016 International Conference on ICT For Smart Society (ICISS). Surabaya: IEEE; 2016. p. 37-41.

3. Voß S, Stahlbock R, Steenken D. Container terminal operation and operations research - a classification and literature review. OR Spectr. 2004 Jan 1;26(1):3-49.

4. Bischoff EE, Ratcliff MSW. Issues in the development of approaches to container loading. Omega. 1995 Aug 1;23(4):377-90.

5. Ambrosino D, Sciomachen A, Tanfani E. Stowing a containership: the master bay plan problem. Transp Res Part A Policy Pract. 2004 Feb 1;38(2):81-99.

6. Stahlbock R, Voß S. Operations research at container terminals: a literature update. OR Spectr. 2007 Nov 12;30(1):1-52.

7. Martello S, Toth P. Knapsack problems algorithm and computer implementation. Chichester: John Wiley \& Sons Ltd.; 1990.

8. Setemen K. Implementasi Algoritma Genetika Pada Knapsack Problem. In: Seminar Nasional Aplikasi Teknologi Informasi 2010 (SNATI 2010). Yogyakarta; 2010.

9. Corry P, Kozan E. Optimised loading patterns for intermodal trains. OR Spectr. 2008 Oct 24;30(4):721-50. 